\title{
CONGENITAL MALFORMATIONS AMONG NEWBORNS IN KENYA
}

Muga $\mathrm{RO}^{1^{*}}$, Mumah SCJ' ${ }^{2}$ and PA Juma ${ }^{3}$

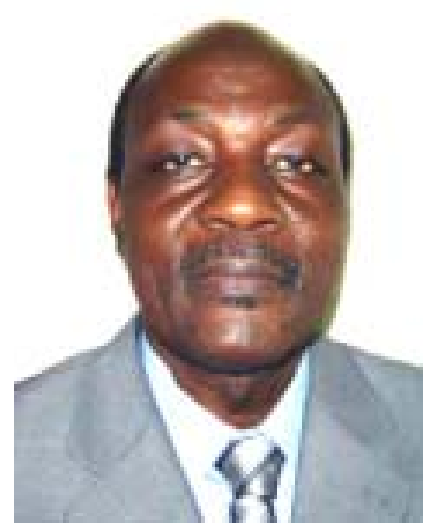

Richard Muga

Corresponding author email: drmuga@yahoo.com

${ }^{1}$ Professor of Paediatrics, Great Lakes University of Kisumu (GLUK). P.O. Box 2224, Kisumu, Kenya.

${ }^{2} \mathrm{PhD}$ (Behavioral Medicine), Department of Psychology, Kenyatta University, P. O. Box 43844-00100, Nairobi, Kenya. Email: scjmumah@yahoo.ca

${ }^{3} \mathrm{PhD}$ (candidate), Great Lakes University of Kisumu (GLUK), P.O. Box 2224, Kisumu, Kenya. Email: atienopam@yahoo.com 


\section{ABSTRACT}

Available literature suggests that congenital malformations are a major cause of prenatal infant deaths and postnatal physical defects $[1,2]$. Therefore, a study was conducted to determine the patterns and incidence of congenital malformations at birth in newborns in Kenya and thereby analyze associated predisposing factors in their mothers. This single cross-sectional survey adopted the quasi-experimental study design to investigate a total of 7,355 consecutive births at the maternity unit of Kenyatta National Referral Hospital over a period of uninterrupted 12 months beginning $8^{\text {th }}$ September to $7^{\text {th }}$ September of the following year. Data collection involved clinical examination of the malformed newborns for final diagnosis using a standard proforma. The study included a control group of new born babies selected systematically among babies who were born during the same study period but had no recognizable defects at birth $(n=210)$. These included normal babies delivered immediately after the malformed newborns. The experimental group comprised the malformed babies $(n=207)$. Mothers were also interviewed for demographic information and data on life style and behavioral risk factors. In this paper only the results of the experimental group are described. A total of 207 malformations were documented. Results showed overall incidence of externally discernible malformations of 28.1 per 1000 total births (28.1/1000). The incidence of major malformations was 15/1000 births. Malformations of musculoskeletal system were the most frequently observed, accounting for $33.9 \%$ of all the major malformations, followed by malformations of the central nervous system (28.6\%). Polydactyl was the most common single malformation with an incidence of 10/1000 total births. Neural tube defects (with an overall incidence of 4.6/1000 births) and chromosomal disorders were also common. On the overall, congenital malformations occurred in proportions that were comparable to other findings in Africa and other parts of the world. These findings highlight the need for stepping up nutritional prevention efforts, for instance, folic acid supplements; strengthening surveillance to monitor trends; and the establishment of a genetic centre in Kenya in order to strengthen local capacity for chromosomal studies, prenatal diagnosis, and genetic counseling on these complex issues.

Key words: Congenital malformations, polydactyl, birth defects. 


\section{INTRODUCTION}

Congenital malformation (a birth defect or a congenital anomaly) is a physical defect present in a baby at birth, irrespective of whether the defect is caused by a genetic factor or by events occurring/existing before or at birth. In a malformation, the development of a structure is arrested, delayed, or misdirected early in embryonic life and the effect is permanent. Congenital malformations can involve many different organs including the brain, heart, lungs, liver, bones, and intestinal tract. These defects can occur for many reasons including inherited genetic conditions, poor diet, toxic exposure of the fetus for example, to alcohol, birth injury and, in many other cases, for unknown reasons.[1] All parents are at risk of having a baby with a birth defect, regardless of age, race, income or residential status.[2] This paper describes a study carried out to determine the pattern of congenital malformations at birth in newborns, thereby analysing the associated predisposing factors in their mothers with a keen focus to nutritional related variables. The study was carried out at Kenya National Hospital $(\mathrm{KNH})$ in Kenya.

Available literature shows that congenital malformations contribute highly to prenatal mortality and postnatal physical defects $[3,4,5]$. In the US for instance, $2-3 \%$ of babies are born with a major congenital malformation.[1]; these include heart defects, cleft lip or palate, Downs syndrome, spinal bifida, and limb defects [6]. Sixteen\% of all neonatal deaths in Queensland were due to congenital malformations [4]. Additionally, 20 percent of late infant deaths were attributable to major congenital malformations in Queensland (ibid). [4]. Literature further indicates that congenital malformations are present in one of every three babies that die in the world [ 7 ] and their effects on a child vary depending greatly on the severity of the defect and whether or not other medical problems are present. Thus, it was interesting to determine the pattern of congenital malformations at birth in newborns and analyse associated predisposing factors in their mothers.

\section{METHODOLOGY}

The study was a prospective survey conducted at the maternity unit of Kenyatta National Hospital (KNH), which is Kenya's leading referral hospital in Nairobi. The study covered an interrupted period of 12 months from $\left(8^{\text {th }}\right.$ September 1983$)$ to $\left(7^{\text {th }}\right.$ September 1984). Data on 7,355 consecutive births were collected during the study period. A total of 207 birth defects were identified. Malformed babies $(n=207)$ were clinically examined for final diagnosis using a standard proforma (with demographic indicators of the newborn, information on clinical examination of the ears, eyes, mouth, neck, chest, CVS, abdomen, genitalia, extremities, CNS and clinical gestation).

Major congenital malformations included defects present at birth which may be fatal and/or handicap the patient throughout life. Minor congenital malformations were classified as those defects with no handicap, for example, skin tag and birth mark. If a newborn had two or more malformations, the system with the most obvious or major malformation was adopted. For instance, a baby with a meningomyeloceole and

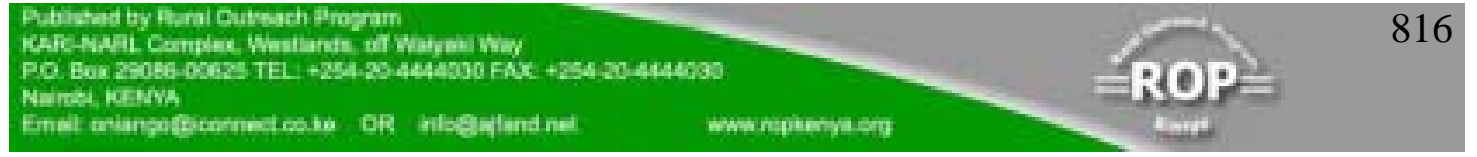


talipes was classified under Central nervous system malformation and counted only once. In cases where a group of malformations constituted a known syndrome or chromosomal disorder, then the syndrome was taken as the diagnosis. Further, only those cardiac malformations which were either confirmed by a pediatric cardiologist or discovered at autopsy were included in the analysis.

Mothers were interviewed with the help of a questionnaire. Information gathered included demographic profile, data on lifestyle and behavioral risk factors including smoking during pregnancy, alcohol consumption and use of contraceptives. Other relevant information included medical history of illness, treatment history, past occurrence of similar birth defects, birth order of index baby and father's age, and social habits. In addition, photographs of the malformed baby were taken for detailed documentation (after obtaining informed consent from the mother). Babies with major congenital malformations were followed up, with daily reviews in the hospital for the first 28 days post-delivery, to determine neonatal outcomes. At discharge, the babies were booked at the paediatric demonstration clinic for follow- up review at the end of the first month of life. Any baby requiring surgical or other specialist attention at this stage was referred to the respective clinic for follow up. Death of a baby from the study population while still in the hospital resulted in a postmortem examination to establish immediate cause.

Descriptive analysis was performed to determine distribution pattern, incidence of malformations and neonatal outcomes. Malformations were classified into major and minor ones.

\section{RESULTS}

During the study period (September 1983 and September 1984), there were 7,230 deliveries resulting in 7,355 newborns (Table 1). Newborns numbering 207 were malformed with an overall incidence of $2.8 \%$ of all live births. Stillbirths were 304 $(4.1 \%)$ out of which $17(5.6 \%)$ were malformed while $1.5 \%$ of the malformations were major. Peak reproductive age group was 20-24 years (range 16-44 years) and mean age of mothers with malformed babies was 26 years (Table 2 ). 


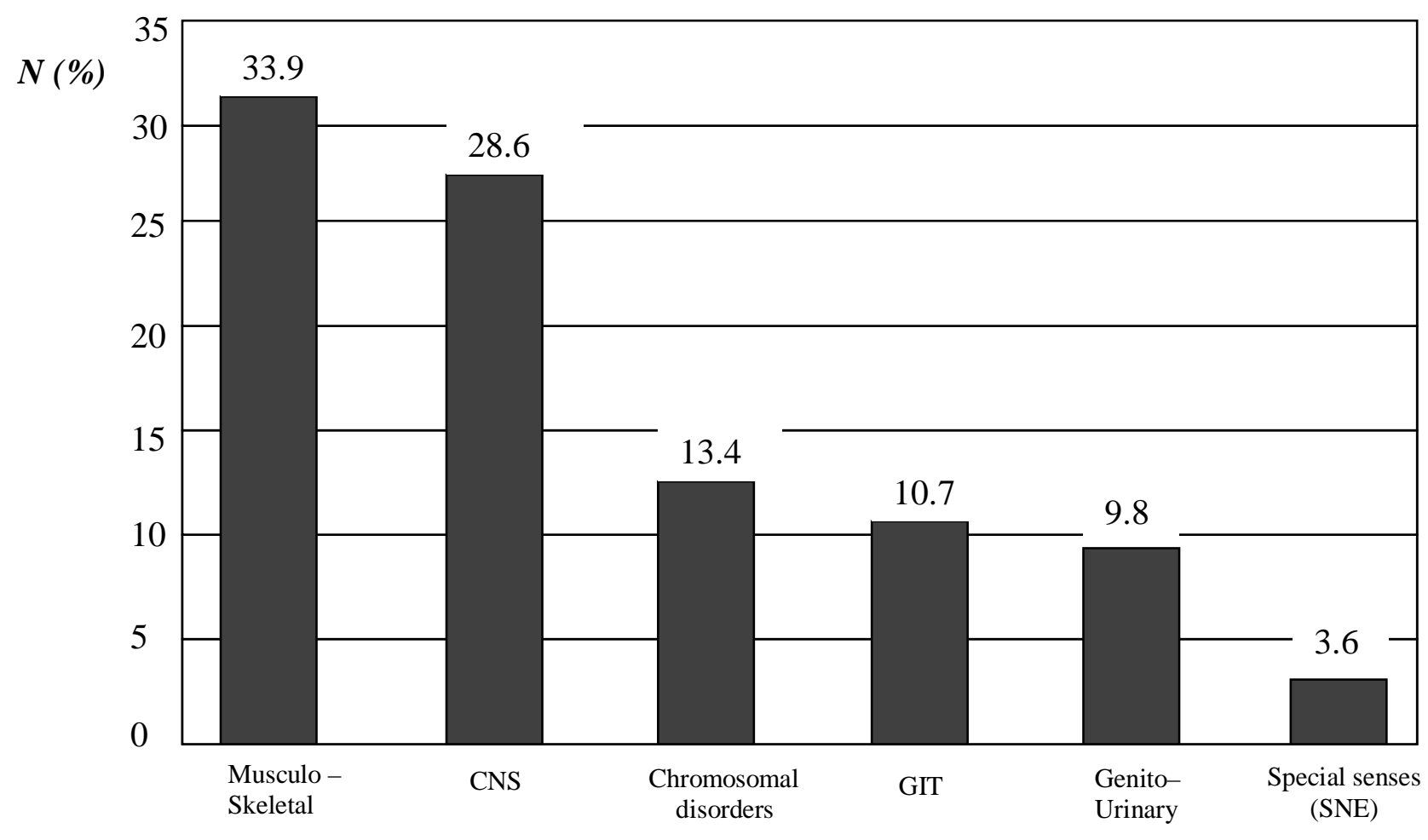

Figure 1: Distribution of major congenital malformations $(n=112)$

Nearly $8 \%$ of the babies with major congenital malformations were of low birth weight $(<2500 \mathrm{gm})$. Musculoskeletal system was the commonest of the malformations, contributing $33.9 \%$ (38) of all major malformations followed by the CNS $28.6 \%$ (32) (Figure 1). Malformations of special senses (skin, nose and ear) were the least common. The overall incidence of Musculo-skeletal (MSS) malformations was $17.3 / 1000$ total births, the commonest malformation being polydactyl $(59.1 \%$ with an incidence of $10.2 / 1000$ births, twice as common in males as females $(\alpha=0.05$, $\mathrm{p}<0.001$ ) (Table 3). Additionally, $40.4 \%$ of the babies who had Musculo-skeletal malformations were low-birth weight as opposed to the $11.9 \%$ of their controls $(\alpha=0.05, p<0.001)$. An analysis into the relationship between mother's age and babies born with MSS malformations (polydactyly excluded) revealed that a greater majority of MSS malformations (69\%) occurred in mothers aged between 20-29 year.

There were 75 cases of polydactyly ( $44 \%$ of which involved both upper and lower limbs attached on the ulnar border of the $5^{\text {th }}$ finger, 34\% unilateral left ulnar border) with an incidence of 10.2/1000 births. Of all these cases, $62.7 \%$ had positive family history of polydactyly. Some $8 \%$ of the babies with polydactyly had other associated major malformations, the commonest being hydrocephalus followed by chromosomal disorders. There were, however, no statistical differences in the birth order of babies born with polydactyly. Further, polydactyly occurred in all maternal age ranges (with 
slight increase in cases born to mothers aged 20-24, corresponding with the peak reproductive age range).

Overall incidence of CNS malformations was 4.6/1000 total births with hydrocephalus being the most common CNS anomaly, contributing $32.4 \%$ (with an incidence of 1.5/1000 births) (Table 4). About 53\% of all the CNS malformations occurred in association with the other system involvement (Figure 2).

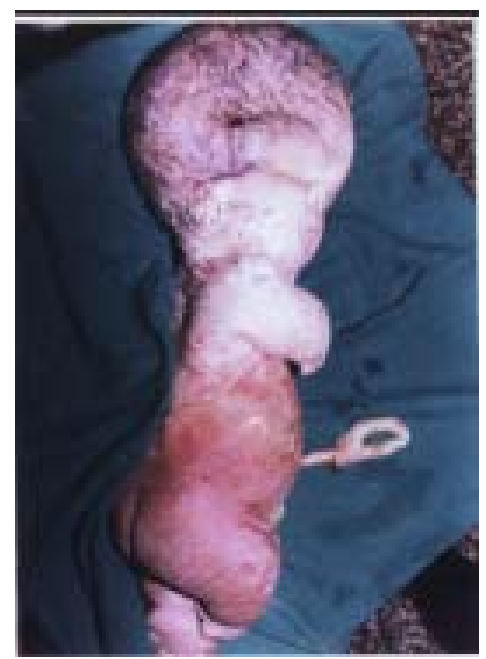

\section{Figure 2: Baby with severe hydrocephalus}

Seventy six percent of all CNS malformations occurred in mothers below age 30 years, with an increment in age, especially from 35 years. Findings regarding the birth order of babies with CNS malformations showed that birth order

"Four" (4) contributed $55.2 \%$ of the cases. Down's syndrome was the leading chromosomal defect contributing to 6 out of the 15 cases with an incidence of $0.82 / 1000$ total births (Table 5). Overall male-female ratio was 2:3, far above the expected 1:1, indicating female preponderance in chromosomal disorders. One hundred and twelve babies had major congenital malformations and $15.1 \%$ (17) of the major congenital malformations were among stillborn babies. Two babies had cardiorespiratory problems; one had TGA and the other diaphragmatic hernia. A baby in the special senses category had bilateral choanal atresia and two babies had ear malformations associated with internal abnormalities. Some malformations found at autopsy were associated with external presenting malformations (Table 7).

Fifty deaths occurred among the 95 live born babies with major malformations giving a fatality rate of $44.6 \%$ (Table 6). Fifty percent (25/50) had CNS malformations of whom 17 were stillborn. CNS defects contributed to most deaths followed by chromosomal $(16 \%)$ and musculo-skeletal (14\%) defects. Based on 7355 births recorded during the study period, the mortality rate due to congenital malformations was $0.7 \%$ of all births. 


\section{DISCUSSIONS}

The incidence of major malformations in this study was $1.5 \%$ of total births. This is comparable to findings of other studies [ 8, 9, 10, 11]. However, other studies have reported higher rates. MacKeon and Record [14] reported two times as many malformations. In another study, McIntosh, et al, could only diagnose $43.2 \%$ of all malformations at birth yet at the end of one year follow-up, the figure had risen to 97\%.[3]. Similar findings were reported by Neel showing that the incidence of congenital malformations in live births in a given population tend to increase with follow-up duration (age) [9]. The incidence found in the present study and those of the prospective studies in different populations were comparable.(Table 8).

There were more malformed male than female infants; however, the difference was not statistically significant.[3, 12,13]. The number of malformed babies appeared to increase with increasing maternal age especially from 35 years and above, who accounted for $13.4 \%$ of all malformed babies.

Musculoskeletal malformations were commonest. Polydactyly accounted for $59.1 \%$ of all musculoskeletal malformations, and 10.2 per 1000 births. It has been recorded since ancient times in the Bible, 11 Samuel 21:20, "And there was a man of great stature who had six fingers and six toes on every hand and foot-“. Drew et al. [17], in Melbourne found polydactyly among newborns at a rate of 0.6 per 1000 births. This was nearly sixteen times lower than the rate in the current series. It is known to be inherited by simple dominant gene mechanism although the condition may be present in all people heterozygous for the gene and the manifestation is very variable. Family history is positive in many cases [18]. Among the CNS malformations, findings showed a combined incidence of anencephaly and myeloceole of 1.9 per 1000 total births. This is consistent with findings of Mati[ 15] in a study in Nairobi which found a combined incidence of 1.1 per 1000 total births. It suffices to say that neural tube defects do occur among Africans contrary to the previous suggestions of Simpkiss and Lowe [16].

\section{CONCLUSION}

Major newborn malformations are often fatal, as illustrated in this study. Prevention, therefore, should be prioritized to the extent possible. There is evidence that improvement of nutrition during conception and during the first trimester can reduce the risk of fatal birth defects $[6,7,19,20,21]$. Appropriate nutritional supplementations are recommended to reduce the risk of congenital malformations; establishment of a genetic centre in order to facilitate chromosomal studies, prenatal diagnosis of congenital malformation [22, 23, 24, 25 ] and genetic counseling in Kenya. There is also need for improved surveillance system for congenital malformations in hospital births to monitor trends in view of increasing environmental pollution due to rapid industrialization in Kenya and in the rest of the developing world. 


\section{ACKNOWLEDGEMENTS}

We take this opportunity to acknowledge our indebtedness to those who assisted us in this research. To the staff who worked in the study areas, especially nursery and labour wards, we thank you very much for your support. To mothers whose newborns were the subjects of this study, we are proud of you because without you, this study could not have been done. 
Table 1: $\quad$ Outcome of deliveries by sex.

\begin{tabular}{lrrr}
\hline Delivery outcome & Males & females & Total \\
\hline Singletons & 3581 & 3525 & 7106 \\
Twins & 124 & 122 & 246 \\
Triplets & 02 & 01 & 03 \\
Live births & 3554 & 3497 & 7051 \\
Still births & 153 & 151 & 304 \\
All malformed & 104 & 103 & 207 \\
\hline \multicolumn{1}{r}{$\mathrm{N}$} & 3705 & 3650 & 7355 \\
\hline
\end{tabular}

Table 2: $\quad$ Mothers' age.

\begin{tabular}{lcc}
\hline $\begin{array}{l}\text { Maternal Age } \\
\text { Range }\end{array}$ & frequency & $\%$ \\
\hline $40-44$ & 05 & 04.5 \\
$35-39$ & 10 & 08.9 \\
$30-34$ & 13 & 11.6 \\
$25-29$ & 31 & 27.7 \\
$20-24$ & 36 & 32.1 \\
$15-19$ & 17 & 15.2 \\
\hline & $\mathrm{N}$ & 112 \\
\hline
\end{tabular}


Table 3: Distribution of musculo-skeletal malformations.

\begin{tabular}{|c|c|c|c|c|c|}
\hline \multirow[b]{2}{*}{ Delivery outcome } & \multicolumn{2}{|c|}{ Sex } & \multirow{2}{*}{$\begin{array}{c}\text { rate per } \\
1000 \text { births }\end{array}$} & \multirow[b]{2}{*}{ freq } & \multirow[b]{2}{*}{$(\%)$} \\
\hline & $\mathrm{m}$ & $f$ & & & \\
\hline Polydactyly & 50 & 25 & 10.2 & 75 & 59.0 \\
\hline Talipes & 12 & 12 & 03.4 & 24 & 18.9 \\
\hline Genurecurvatum & 04 & 05 & 01.6 & 09 & 07.0 \\
\hline Achrondroplasia & 06 & 00 & 00.8 & 06 & 04.7 \\
\hline Intra-uterine amputation (amniotic bands) & 01 & 02 & 00.4 & 03 & 02.4 \\
\hline Syndactyly & 02 & 01 & 00.4 & 03 & 02.4 \\
\hline Craniovertebral anomaly & 02 & 00 & 00.3 & 02 & 01.6 \\
\hline Amelia upper limbs & 01 & 00 & 00.1 & 01 & 00.8 \\
\hline Osteogenesis imperfects & 01 & 00 & 00.1 & 01 & 00.8 \\
\hline Hypoplastic femur & 00 & 01 & 00.1 & 01 & 00.8 \\
\hline Hypoplastic mandible (severe) & 00 & 01 & 00.1 & 01 & 00.8 \\
\hline Oxycephaly & 00 & 01 & 00.1 & 01 & 00.8 \\
\hline $\mathrm{N}$ & 79 & 48 & 17.3 & 127 & 100.0 \\
\hline
\end{tabular}


Table 4: $\quad$ Malformations of the CNS.

\begin{tabular}{|c|c|c|c|c|c|}
\hline \multirow[b]{2}{*}{ Malformation } & \multicolumn{2}{|c|}{ Cases } & \multirow{2}{*}{$\begin{array}{c}\text { rate per } 1000 \\
\text { births }\end{array}$} & \multirow[b]{2}{*}{ freq } & \multirow[b]{2}{*}{$(\%)$} \\
\hline & single & multiple & & & \\
\hline Hydrocephalus & 03 & 08 & 01.5 & 11 & 32.4 \\
\hline Ancencephalus & 06 & 04 & 01.4 & 10 & 29.4 \\
\hline Microcephaly & 05 & 01 & 00.8 & 06 & 17.6 \\
\hline Spina bifida & 01 & 03 & 00.5 & 04 & 11.8 \\
\hline Cyclops & 00 & 02 & 00.3 & 02 & 05.9 \\
\hline Encephaloceole & 01 & 00 & 00.1 & 01 & 02.9 \\
\hline $\mathrm{N}$ & 16 & 18 & 04.6 & 34 & 100.0 \\
\hline
\end{tabular}

Table 5: Chromosomal defects.

\begin{tabular}{lccc}
\hline malformation & rate per 1000 births & $\mathrm{n}$ & maternal age \\
\hline Down's syndrome & 0.82 & 06 & 31.0 \\
Edward's syndrome & 0.40 & 03 & 25.7 \\
Turner's syndrome & 0.27 & 02 & 29.0 \\
Patau's syndrome & 0.14 & 01 & 20.0 \\
Unclassified & 0.27 & 03 & 28.3 \\
\hline \multicolumn{1}{c}{$\mathrm{N}$} & 2.00 & 15 & $X=24.4$ \\
\hline
\end{tabular}




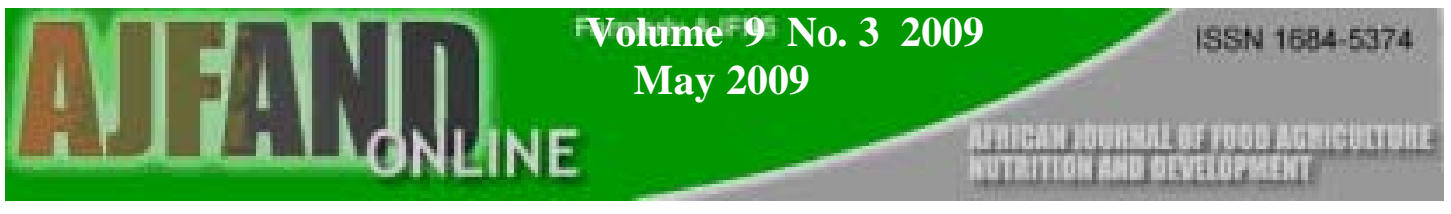

Table 6: Distribution of deaths according to system involvement.

\begin{tabular}{lccc}
\hline & System & $\mathrm{f}$ & $\%$ \\
\hline (SB 17 + 8 NND) & CNS & 25 & 50 \\
Chromosomal disorders & 08 & 16 \\
Musculo-skeletal & 07 & 14 \\
GIT & 03 & 06 \\
Special senses & 03 & 06 \\
Genito-urinary & 02 & 04 \\
Cardio-respiratory & $\mathrm{N}$ & 02 & 04 \\
\hline
\end{tabular}


Table 7: $\quad$ Malformations found at autopsy in association with external presenting malformations.

\begin{tabular}{|c|c|c|}
\hline Cases & Presenting external malformations & Internal malformations \\
\hline Case 01 & Trisomy 18 & Tetrallogy of Fallots, Horse-shoe kidney. \\
\hline Case 02 & Trysomy 18 with hydromnios & High VSD, Horse-shoe kidney. \\
\hline Case 03 & Trysomy 18 & Absent left atrium, Hypoplastic left ventricle, large PDA. \\
\hline Case 04 & Cyclops & Secondary hydrocephalus, PDA, atresia of gall bladder, adrenal \\
\hline Case 05 & Cyclops & agenesis. \\
\hline Case 06 & Hypoplastic left ear & Hydrocephalus. \\
\hline Case 07 & Bilateral anotia & Left diaphragmatic hernia, horse-shoe kidney, double ureters. \\
\hline Case 08 & Bilateral deformed ear & Biliary atresia, no gall bladder, undescennded testes. \\
\hline Case 09 & Microcephaly with & Polycystic kidneys, ASD, Hepatic fibrosis. \\
\hline Case 10 & oligohydromnios & Polycystic kidneys. \\
\hline Case 11 & Bilateral TEV, Prune belly & Posterior urethral valves, hydroureters. \\
\hline Case 12 & syndrome & Fused cervical vertebrae, Mediastinal cyst, PDA, VSD. \\
\hline Case 13 & Short webbed neck with CCF & PDA. \\
\hline \multirow[t]{5}{*}{ Case 14} & Intrauterine amputation amniotic & Total situs inversus \\
\hline & bands & TGA. \\
\hline & Situs inversus with lumbar & \\
\hline & meningoceole & \\
\hline & Hepatomegaly in CCF & \\
\hline
\end{tabular}


Table 8: Frequency of congenital malformations found in some prospective studies in different populations.

\begin{tabular}{|c|c|c|}
\hline Author and year & No of births & Percentage malformed \\
\hline $\begin{array}{c}\text { McIntosh et al 1954, } \\
\text { New York }\end{array}$ & 5964 & $7.0 \%$ all malformations \\
\hline $\begin{array}{c}\text { Neel 1958 Japan } \\
\text { Simpkiss and Lowe 1961 } \\
\text { Kampala }\end{array}$ & 64,567 & $1.02 \%$ major malformations \\
\hline $\begin{array}{c}\text { Marden et al 1964 } \\
\text { Lesi 1968 Lagos, } \\
\text { Nigeria }\end{array}$ & 3016 & $5.4 \%$ all malformations \\
\hline $\begin{array}{c}\text { Van Regemorter, et at } \\
\text { Brussels }\end{array}$ & 16,720 & $1.4 \%$ all malformations \\
\hline $\begin{array}{c}\text { *Muga 1984 } \\
\text { Present Series }\end{array}$ & 7355 & $1.9 \%$ major malformations \\
\hline
\end{tabular}




\section{REFERENCES}

1. Lee K, Khoshnood B, Chen L, Wall S, Cromie W and R Mittendorf Infant Mortality from Congenital Malformations in the United States, 19701997 Obstetrics \& Gynecology 2000; 98: 620-627.

2. Schempf A, Branum A, Lukacs A and KC Schoendorf The Contribution of Preterm Birth to the Black-White Infant Mortality Gap, 1990 and 2000. Am J Public Health, 2007; 97: 1255-1260.

3. McIntosh R, The Incidence of Congenital Malformations: A study of 5964 Pregnancies. Pediatrics, 1958, 14: 505-22.

4. Gustavson $\mathbf{K}$ and $\mathbf{H}$ Jorulf Recurrence Risks in a Consecutive Series of Congenitally Malformed Children Dying in the Perinatal Period. Clin Genet, 1976; 9: 307-314.

5. Khoshnood B, De Vigan C, Vodovar V, Goujard J, Lhomme A, Bonnet D and F Goffinet Trends in Prenatal Diagnosis, Pregnancy Termination, and Perinatal Mortality of Newborns with Congenital Heart Disease in France, 1983-2000: A Population-Based Evaluation. Pediatrics, 2005; 115: 1: 95 - 101.

6. Berry J, Li $\mathbf{Z}$ and J Erickson Prevention of Neural Tube Defects with Folic Acid in China NewEngJ Med, 1999; 341: 1485- 1490.

7. Hernández-Díaz, Werler M, Walker $\mathbf{A}$ and $\mathbf{A}$ Mitchell Folic Acid Antagonists During Pregnancy and the Risk of Birth Defects. $J$ of medicine; 2000 .

8. Holmes LB Inborn Errors of Morphogenesis. Engl J Med, 1974: 763-73.

9. Neel JV A Study of Major Congenital Defects in Japanese Infants. Am J Hum Genet, 1958: 10: 399-43.

10. Marden PM, Smith DW and Mcdonald MJ Congenital Anomalies in the Newborn Infant, Including Minor Variations. J Pediatrics, 1964, 6: 357-361

11. Van Regemorter N Major Congenital Malformations in 5448 Newborns: Comments on Genetic Counseling and Prenatal Diagnosis. Acta Paediatr Belg, 1976; 34: 73-81.

12. Skinner R Genetic counseling. In: AEH Emery, DL Rimoin (Eds). Principles and Practice of Medical Genetics, Vol. 2. Edinburgh, Churchill Livingstone, $1983 ; 1429-146$.

13. WHO. World Health Organization. Community Approaches to the Control of Hereditary Diseases. WHO, Geneva, 1985

14. Mackeown T and RG Record Malformations in a population observed for five years after birth. Ciba Foundation Symposium on congenital malformations, 1960. London J and A Churchill.

15. Mati JKG, Aggarwal VP, Sanghvi H C G, Lucas S and R Corkhill The Nairobi Birth Survey. The study design, the population and outline of results, J. Obstet,Gyn .East. Afr. 1982, 1: 132- 140 . 
16. Simpkiss $\mathbf{M}$ and $\mathbf{A}$ Lowe Congenital anomalies in A African newborns. Arch. Dis. Child 1961, 36 : 404- 500.

17. Drew $\mathbf{J} \mathbf{H}$, Parkinson $\mathbf{P}$, Walstab $\mathbf{J} \mathbf{E}$ and $\mathbf{A B}$ Norman Incidence and types of congenital malformations in newborn infants. Med. J .Aust . 1977, 1 : 945-960.

18. Lesi F E A. A study of congenital malformations in newborns in Lagos , Nigeria. Ph .D. Thesis 1968.

19. Shaw GM, O'Malley CD, Wasserman CR, Tolarova MM and EJ Lammer Maternal Periconceptional Use of Multivitamins and Reduced Risk for Coronary Heart Defects and Limb Deficiencies Among Offspring. Am J Med Genet 1995; 59: 536-545.

20. Czeizel AE, Toth M, and M Rockenbauer Population-Based Case Control Study of Folic Acid Supplementation During Pregnancy. Teratology 1996; 53: 345-351.

21. Werler MM, Hayes C, Louik C, Shapiro S and AA Mitchell Multivitamin Supplementation and Risk of Birth Defects. Am J Epidemiol 1999, 150: 675682.

22. Stoll C Usefulness of a Registry of Congenital Malformations for Genetic Counseling and Prenatal Diagnosis. Clin Genet, 1986, 29; 204-10.

23. Van Regemorter N Major Congenital Malformations in 5448 Newborns: Comments on Genetic Counseling and Prenatal Diagnosis. Acta Paediatr Belg, 1976; 34: 73-81.

24. Van Regemorter $\mathbf{N}$ Congenital Malformations in 10000 Consecutive Births in a University Hospital: Needs for Genetic Counselling and Prenatal Diagnosis. $J$ Paediatr, 1984; 3: 386-390

25. Worcester J, Stevenson SS and RG Rice 677 Congenitally Malformed Infants and Associated Digestational Characteristics. Pediatrics, 1950; 6: 208-222. 